\title{
Contribuições da Semiótica aos estudos toponímicos: estudo de caso dos topônimos das comunidades rurais de Santo Antônio de Jesus ${ }^{1}$
}

\author{
Contributions of semiotics to the toponymic study: case study of toponyms rural \\ communities of Santo Antônio de Jesus
}

\begin{abstract}
Lana Cristina Santana de Almeida*
Resumo: A Toponímia é uma disciplina científica ligada à Lexicologia e tem como objeto de pesquisa os nomes de localidade; trata-se de um estudo interdisciplinar que se utiliza dos fundamentos de outras teorias para legitimar a significação e a categorização atribuída aos topônimos. Entre essas ciências está a Semiótica, cujos princípios podem ser aplicados aos estudos toponímicos, pois os nomes de lugares são signos que possuem como característica a motivação linguística, isto é, entre esses signos e o seu referente há um vínculo que colabora para a identificação e representação do lugar. Dessa forma, este artigo dedica-se a apresentar fundamentos da Semiótica que podem auxiliar a compreensão a respeito da motivação semântica presente nos topônimos. Para tanto, toma-se como corpus os nomes das comunidades rurais da cidade de Santo Antônio de Jesus-BA e utiliza-se como fundamentação teórica, principalmente, as ideias dos seguintes autores: Peirce $(1975,2005)$, Santaella $(1987,2004)$, Ullmann (1964), Saussure (1969), Ogden e Richards (1976), Guiraud (1980) e Dick (1990a, 1990b, 1999, 2001). Palavras-chave: Toponímia; Lexicologia; Semiótica; Santo Antônio de Jesus.
\end{abstract}

Abstract: Toponymy is a scientific discipline related to Lexicology and it has as object of research local names, being characterized as an interdisciplinary study which uses the foundations of other theories to legitimize the significance attributed to the categorization and toponyms. Among these sciences is Semiotics, whose principles can be applied to Toponymic studies, once names of places are signs that have linguistic motivation, that is, among these signs and their references is a bond that contributes to the identification and representation of place. Thus, this paper aims at presenting semiotics foundations that can help to explain semantic motivation about the use of toponyms. The names of rural communities were compiled as a corpus of the city of Santo Antônio de Jesus, Bahia. Theoretical assumptions based on Peirce (1975, 2005), Santaella (1987, 2004), Ullmann (1964), Saussure (1969), Ogden e Richards (1976), Guiraud (1980) and Dick (1990a, 1990b, 1999, 2001) were adopted.

Keywords: Toponymy; Lexicology; Semiotics; Santo Antônio de Jesus.

\section{Introdução}

Os estudos onomásticos correspondem à área da Lexicologia direcionada para o estudo do nome próprio. Essa ciência subdivide-se em duas áreas: Antroponímia - estudo do nome individual de pessoas, sobrenomes de família e alcunhas - e Toponímia - estudo dos nomes próprios de lugares; ambas interessam-se pela palavra quando esta é utilizada no campo da

\footnotetext{
${ }^{1}$ Este artigo é parte integrante da dissertação de mestrado "O léxico toponímico das comunidades rurais de Santo Antônio de Jesus: uma análise semântica e sociocultural", defendida pela autora desse artigo em 30/11/12.

* Mestre em Língua e Cultura pelo Programa de Pó-graduação do Instituto de Letras da Universidade Federal da Bahia- UFBA.
} 
denominação, isto é, no campo onomástico. Embora a pesquisa do léxico onomástico apresente uma metodologia específica, seu objeto de análise - o nome - integra-se, indubitavelmente, ao léxico pleno das línguas naturais, seguindo, portanto, todos os padrões formais da língua em estudo.

Inicialmente, os estudos linguísticos direcionados ao léxico estabeleciam diferenças entre o nome comum e o nome próprio. Essa diferenciação consistia na ideia de que os nomes comuns sempre significam algo, enquanto que os nomes próprios apenas identificam seus referentes (ULLMANN, 1964). Nessa concepção, sem o objeto ao qual o nome próprio se refere, não é possível estabelecer uma relação de causalidade entre o nome e o pensamento e, por conseguinte, não há significação, entretanto, Dick (1999) afirma que os nomes próprios não apenas identificam, mas também significam, pois eles representam as percepções que o denominador possui a respeito do seu entorno social. O que ocorre é que essa categoria de nomes ultrapassa os limites do sistema linguístico para direcionar-se ao extralinguístico e, apesar de ser um signo referencial, ele não foge aos padrões conceituais que um símbolo linguístico deve possuir; porém, apresenta um diferencial: a motivação semântica.

Assim, como mantém uma ligação direta com o seu referente, o topônimo possui um grande valor documental, uma vez que, no ato da nomeação, o denominador busca, em seu repertório linguístico, palavras que representem sua cultura, sua história e aspectos geográficos da sua região, incorporando-os ao nome dado ao local. Para entender melhor essa relação, a Semiótica, ciência dos signos, torna-se uma grande colaboradora dos estudos toponímicos; sendo assim, este artigo tem como objetivo apresentar alguns conceitos presentes na teoria dos signos, elaborada por Charles Sanders Peirce e que podem ser aplicados à Toponímia. Em seguida, serão analisados, à luz da Semiótica, os topônimos das comunidades rurais de Santo Antônio de Jesus.

\section{O signo linguístico e os estudos semióticos}

A ciência da Semiologia, assim chamada por Saussure (1969), também é conhecida como Semiótica, nomenclatura dada por autores norte-americanos. Essa ciência tem como objeto de estudo os signos; entretanto, ela não se detém apenas ao signo linguístico, mas, sim, a todo e qualquer signo, pois esses são a própria expressão da linguagem, uma vez que o homem utiliza diversas formas de expressão que ultrapassam os limites do código falado ou escrito. Sendo assim, o campo de investigação da Semiótica 
é tão vasto que chega a cobrir o que chamamos de vida, visto que, desde a descoberta da estrutura química do código genético, nos anos 50, aquilo que chamamos de vida não é senão uma espécie de linguagem, isto é, a própria noção de vida depende da existência de informação no sistema biológico. Sem informação não há mensagem, não há planejamento, não há reprodução, não há processo e mecanismo de controle e comando. [...] Sem a linguagem seria impossível a vida, pelo menos como a conceituamos agora: algo que se reproduz, que tem um comportamento esperado e certas propensões. Nessa medida, não apenas a vida é uma espécie de linguagem, mas também todos os sistemas e formas de linguagem tendem a se comportar como sistemas vivos, ou seja, eles reproduzem, se readaptam, se transformam e se regeneram como as coisas vivas. [...] Caracterizado o campo de abrangência da Semiótica, podemos repetir que ele é vasto, mas não indefinido. O que se busca descrever e analisar nos fenômenos é sua constituição como linguagem. [...] a Semiótica busca divisar e deslindar seu ser de linguagem, isto é, sua ação de signo (SANTAELLA, 1987, p. 2-3).

Portanto, a ação do signo é puramente interpretativa e autogerativa, pois para se explicar um signo, é necessário criar outros signos e isso é infinito. O signo é a linguagem em função mediadora entre o homem e as coisas que ele percebe no mundo ao seu redor, sejam elas existentes ou em possibilidade de existir.

Ao elaborar sua teoria, Saussure afirmava que a Linguística fosse integrada à Semiologia. "[...] As leis que a Semiologia descobrir serão aplicáveis à Lingüística e esta se achará dessarte vinculada a um domínio bem definido no conjunto dos fatos humanos". (SAUSSURE, 1969, p. 24). E a missão do linguista seria "[...] definir o que faz da língua um sistema especial no conjunto dos fatos semiológicos.” (SAUSSURE, 1969, p. 25)

Quase na mesma época em que Saussure apresenta sua teoria sobre os signos, nos Estados Unidos, Charles Sanders Peirce, cientista matemático e filósofo, também apresenta ao mundo a ciência da Semiótica, que para ele corresponde à Lógica, uma vez que "[...] a lógica é a ciência das leis necessárias gerais dos Signos e, especialmente, dos Símbolos" (PEIRCE, 2005, p. 29). Como já dito, a Semiótica tem um campo vastíssimo, mas a intenção de Peirce não era criar uma ciência que substituísse as outras, mas, sim, criar uma ciência que colaborasse no entendimento das demais, já que tudo é linguagem e, por conseguinte, tudo é signo.

Apesar de criarem teorias a respeito do signo, Peirce e Saussure possuem ideias divergentes a respeito do assunto. A principal encontra-se no fato da teoria de Saussure analisar os fenômenos linguísticos sempre a partir de dicotomias, assim, em sua teoria o signo linguístico apresenta-se como uma díade: signo linguístico é igual à relação que se estabelece 
entre significante/significado. Peirce, por sua vez, baseia-se em uma tríade: signo é igual à união do signo/objeto/interpretante.

Segundo Peirce, toda comunicação abrange diferentes fenômenos, os quais podem ser qualquer coisa que surge na mente das pessoas: um sonho, um delírio, um cheiro, uma imagem (apud SANTAELLA, 2004), isto é, tudo que faça parte do mundo concreto ou abstrato. Esses fenômenos podem ser intuídos por qualquer ser humano que utilize seus sentidos para observálos, percebê-los e interpretá-los. Sendo assim, esse cientista determina que “[...] a palavra Signo será usada para denotar um Objeto perceptível, apenas imaginável ou mesmo insuscetível de ser imaginado em um determinado sentido [...]" (PEIRCE, 1975, p. 95).

Diante da abrangência dos fenômenos, Peirce vê a necessidade de dividi-los em categorias universais e, consequentemente, dividir também os tipos de signos, os quais irão corresponder às categorias formuladas. Assim, ele define três tipos de categorias, desenvolvidas ao nível da consciência, a que ele chama de tríade na Psicologia, capazes de explicar os fenômenos, a saber: a primeiridade, a secundidade e a terceiridade.

As verdadeiras categorias da consciência são: primeira, sentimento, a consciência que pode ser compreendida como um instante do tempo, consciência passiva da qualidade, sem reconhecimento ou análise; segunda consciência de uma interrupção no campo da consciência, sentido de resistência, de um fato externo ou outra coisa; terceira, consciência sintética, reunindo tempo, sentido de aprendizado (PEIRCE, 2005, p. 14).

Verifica-se, portanto, que a primeiridade refere-se a um nível imediato da consciência a respeito de uma qualidade singular, características percebidas no momento presente como, por exemplo, a percepção da cor de um objeto, desvinculada do próprio objeto, somente a qualidade de ser vermelho, azul, amarelo ou qualquer outra cor; somente a possibilidade das impressões, dos sentimentos que a cor possa trazer; ela, a qualidade, pura e simplesmente. A secundidade, por sua vez, pressupõe uma existência. Por exemplo, a qualidade da cor precisa ser materializada em um elemento concreto, assim a consciência registra o que existe, mas não a partir de uma possibilidade de vir a existir, mas já como um registro de concretização. A terceiridade é o lugar em que a inteligibilidade se torna mais proeminente, pois nessa categoria são processadas as representações legítimas do Signo, isto é, quando se aprende que uma coisa encontra-se "[...] numa tal relação com um outro que, para certos propósitos, é considerado por alguma mente como se fosse outro" (PEIRCE, 2005, p. 61). 
A partir dessas categorias fundamentais do pensamento, Peirce criou três classes de Signo, que serviram de base para dez outras classes; entretanto, serão analisadas, aqui, apenas as três principais. Vale lembrar que as categorias não são estanques e tornam-se perceptíveis entre si, dessa forma, a secundidade pressupõe a primeiridade e a terceiridade poderá pressupor tanto a primeiridade, quanto a secundidade.

Assim, a primeiridade cria um quase signo ou um quali-signo, já que seriam sentimentos, qualidades percebidas em uma consciência imediata sobre algum objeto; a secundidade supõe um binômio, a qualidade associada à existência do objeto, razão pela qual se cria, nessa categoria, um sin-signo, que remete a existência de algo singular pertencente a um universo ao qual faz parte.

Já a terceiridade é o lugar em que os signos desempenham o seu caráter mais genuíno, cria-se o legi-signo, assim chamados porque os signos são criados a partir de leis. Trata-se de signos concebidos, em sociedade, através de acordos implícitos e para entendê-los é preciso aprendê-los e interpretá-los e não apenas percebê-los. Eem cada ação interpretativa, o signo expõe seu caráter de mediador social e seu caráter infinito, pois interpretar um signo significa gerar outro signo.

Assim, Peirce (1975) afirma que

um Signo, ou Representamem, é algo que, sob certo aspecto ou de algum modo, representa alguma coisa para alguém. Dirige-se a alguém, isto é, cria na mente dessa pessoa um signo equivalente ou talvez um signo melhor desenvolvido. Ao signo, assim criado, denomino Interpretante do primeiro signo. O signo representa alguma coisa, seu Objeto. Coloca-se no lugar desse objeto, não sob todos os aspectos, mas com referência a um tipo de idéia que tenho, por vezes, denominado o fundamento do representamem. (PEIRCE, 1975, p. 94. Grifo do autor.)

Fica-se entendido, a partir da afirmação de Peirce, que o signo não é o objeto, ele está em seu lugar e tem a condição de afetar a mente de um intérprete (aquele que vê, lê ou ouve o signo), isto é, provocar-lhe uma reação de interpretação, em busca de significado e, como resultado dessa reação, surge outro signo, nomeado interpretante, que terá ação mediadora de significação entre o representamem e o objeto a que ele se refere. Portanto, o interpretante do signo não é uma pessoa, é um outro signo, o qual não precisa necessariamente ser uma palavra, pode ser uma imagem, um olhar, um gesto, um sentimento, enfim, qualquer reação que o representamem venha a provocar no intérprete. 
O diagrama a seguir mostra as relações estabelecidas nas representações e interpretações construídas a partir de um Signo².

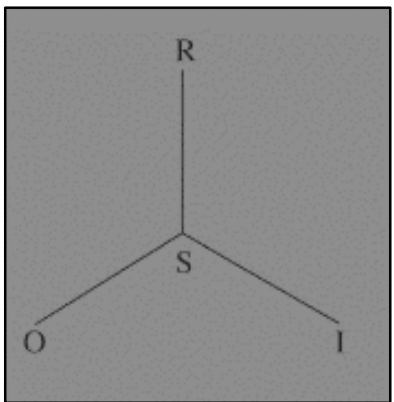

Figura 1 - Processo semiótico na visão de Peirce. Fonte: NADIN, 2011,p. 110.

Dessa forma, observando as categorias e a relação triádica do Signo, tem-se a seguinte classe de signos que ocupam o lugar do Representamem:

Quadro 1- Classificação dos signos na visão de Peirce

\begin{tabular}{|l|c|}
\hline SIGNOS DAS CATEGORIAS & SIGNOS DO \\
FUNDAMENTAIS DO PENSAMENTO & REPRESENTAMEM \\
\hline $1^{\mathrm{a}}$ QUALI-SIGNO & ÍCONE \\
\hline $2^{\mathrm{a}}$ SIN-SIGNO & ÍNDICE \\
\hline $3^{\mathrm{a}}$ LEGI-SIGNO & SÍMBOLO \\
\hline
\end{tabular}

Peirce $(1975,2005)$ afirma que o ícone e o índice não são signos genuínos; são signos degenerados, pois, são signos que prescindem da relação triádica R-O-I (representamem, objeto e interpretante). Um ícone é um quase signo porque apresenta a relação R-I (representamem e interpretante), ele não precisa da presença de um objeto para que uma mente possa percebê-lo, ele apenas apresenta um sentimento, qualidade ou impressão sem que precise necessariamente sua corporificação em um objeto. Um som, por exemplo, quando escutado, é percebido pela audição e imediatamente sensações são provocadas, sem que seja necessário conhecer de qual objeto ele está partindo.

No entanto, porque não representam efetivamente nada, senão formas e sentimentos (visuais, sonoros, táteis, viscerais...), os ícones têm um alto poder

\footnotetext{
${ }^{2}$ A palavra signo quando grafada por letra maiúscula deve ser entendida como uma função sígnica de representação que envolve os três elementos da relação: representamem, objeto e interpretante. Quando grafada com letra minúscula refere-se ao representamem, ou seja, o signo que ocupa o lugar do objeto ou ao signo que ocupa o lugar do interpretante.
} 
de sugestão. Qualquer qualidade tem, por isso, condições de ser um substituto de qualquer coisa que a ele se assemelhe. Daí que, no universo das qualidades, as semelhanças proliferem. Daí que os ícones sejam capazes de produzir em nossa mente as mais imponderáveis relações de comparação (SANTAELLA, 1987, p.14).

Já o índice é um signo degenerado por manter uma relação diádica entre o R- O (representam- objeto). Ele possui um caráter singular, está no papel de representar o objeto por uma relação de contiguidade que mantém com ele, por isso ele dispensa a ação do interpretante, mas sem o objeto sua função de representação não existiria, uma vez que um refere-se diretamente ao outro. Daí ele ser nomeado como sin-signo ( $\sin$ - de singular), pois ele é singular, já que faz parte do universo que representa. A fumaça, por exemplo, é um índice de que há algo pegando fogo; um trovão é um índice de tempestade, cheiro de terra molhada é um índice de chuva. É válido lembrar que a secundidade, categoria a qual o índice faz parte, pressupõe a primeiridade, portanto, os índices estão permeados de ícones, já que estes apresentam as qualidades, enquanto aqueles representam as qualidades corporizadas.

Entretanto, Peirce ressalta que um índice é

um signo, ou representação, que se refere a seu objeto não tanto em virtude de uma similaridade ou analogia qualquer com ele, nem pelo fato de estar associado a caracteres gerais que esse objeto acontece ter, mas sim por estar numa conexão dinâmica (espacial inclusive) tanto com o objeto individual, por um lado, com os sentidos ou a memória da pessoa a quem serve de signo (PEIRCE, 2005, p. 74).

Os símbolos são signos genuínos, uma vez que manifestam integralmente a tríade R-OI (representamem - objeto - interpretante). Peirce define o símbolo da seguinte forma:

Um símbolo [...] não pode indicar uma coisa particular qualquer: ele denota uma espécie de coisa. E não apenas isso como também, em si mesmo, uma espécie e não uma coisa singular. Podemos escrever a palavra 'estrela', porém isso não faz, de quem a escreveu, o criador da palavra, assim como, se apagarmos a palavra, não a destruímos. A palavra vive na mente dos que a usam. Mesmo que estejam dormindo, ela existe em suas memórias. [...] Os símbolos crescem. [...] Estes signos mentais são de natureza mista; denominam-se conceitos suas partes-símbolos. Se alguém cria um novo símbolo, ele o faz por meio de pensamentos que envolvem conceitos. Assim, é apenas a partir de outros símbolos que um novo símbolo pode surgir. [...] Um símbolo, uma vez existindo, espalha-se entre as pessoas. No uso e na prática, seu significado cresce (PEIRCE, 2005, p. 74). 
Portanto, o signo genuíno, o símbolo, apresenta uma relação lógica e ao mesmo social, pois não se volta apenas para a apresentação de qualidades, sentimentos ou representações a partir da existência dos objetos. O signo criado, pelo interpretante, a partir de um símbolo, possui uma ação mediadora prioritariamente interpretativa, que tende a definições, generalizações e, por conseguinte, a abstrações. Contudo, não se pode esquecer que os símbolos também pressupõem a primeiridade e a secundidade, em outras palavras, pressupõem as hipóteses levantadas diante das qualidades e as referências espaciais e associativas a partir da existência do objeto.

Na visão de Saussure (1969), o signo linguístico integra-se à categoria da terceiridade, cujo representamem é um símbolo, uma vez que este possui um caráter social e sua criação ou mudança independe da vontade do usuário da língua, ele apenas recebe a língua como uma herança social.

No entanto, ao excluir o objeto extralinguístico e a ação do usuário da língua, Saussure retira do signo linguístico o caráter dinâmico que possui, pois os interpretantes são construídos através de impressões, de conexões, das relações interpessoais e essas não permanecem estáticas, transformam-se. Nesse ponto, vê-se mais uma diferença entre Saussure e Peirce, pois, enquanto este atribui um caráter diacrônico - já que a percepção que os intérpretes têm de um mesmo objeto diferencia-se de acordo com o tempo - aquele analisa o signo linguístico sincronicamente, ou seja, em seu caráter imediato.

Entretanto, a teoria de Peirce acha um ponto de conexão com a teoria de Saussure no que diz respeito à arbitrariedade do signo linguístico. O significado construído a partir da relação triádica é um processo mental e, ao mesmo tempo, social, não existindo uma relação direta entre o objeto extralinguístico e o signo, enquanto símbolo.

A convicção de que o signo linguístico é arbitrário, leva Saussure (1969) a afirmar que todo signo é imotivado. No entanto, é preciso analisar mais precisamente essa afirmação, pois o próprio Saussure concluirá, que apesar do signo ser arbitrário, existem palavras que apresentam graus relativos de arbitrariedade, portanto existem signos que possuem motivação linguística.

Entre outros pesquisadores que investigaram as relações entre as palavras e as coisas que elas nomeiam, citam-se Ogden e Richards (1976), cientistas que tomaram como base a relação triádica proposta por Peirce. Em seus estudos, eles afirmaram que há relações de causa entre um símbolo e o pensamento e entre o pensamento e o referente; para tanto, os autores 
elaboraram um diagrama, ilustrando sistematicamente as relações causais que surgem no processo comunicativo e a relação de representação entre o símbolo e seu referente.

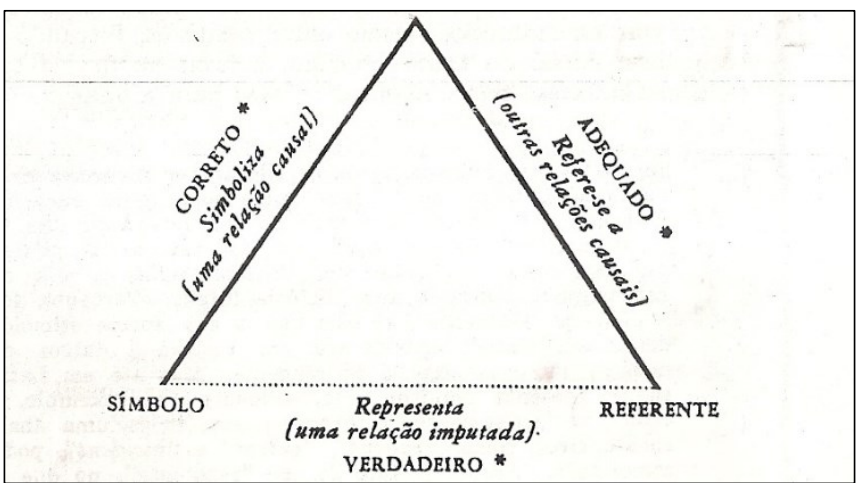

Figura 2 - Triângulo semiótico. Fonte: OGDEN e RICHARDS, 1976, p. 32.

Verificando a relação entre símbolo e pensamento, Ogden e Richards constatam que

quando falamos, o simbolismo que empregamos é causado, em parte, pela referência que estamos fazendo e, em parte, pelos fatores sociais e psicológicos - a finalidade da referência que estamos fazendo, o efeito proposto dos nossos símbolos sobre outras pessoas e a nossa própria atitude. Quando ouvimos o que foi dito, os símbolos fazem com que desempenhemos um ato de referência e ao mesmo tempo, com que tenhamos uma atitude que, de acordo com as circunstãncias, será mais ou menos semelhante ao ato e à atitude de quem falou. (OGDEN; RICHARDS, 1976, p. 32)

As relações estabelecidas entre o pensamento e o referente podem ser mais ou menos diretas, como quando se pensa em algo que se vê ou algo para onde a atenção é direcionada; ou as relações podem ser indiretas, o que ocorre quando se pensa sobre algo, isso leva a uma cadeia de pensamentos e, consequentemente, a uma cadeia infinita de símbolos.

Observando o triângulo semiótico, verifica-se que as relações causais são representadas por linhas sólidas, enquanto que a linha que liga o símbolo ao referente é pontilhada, por se tratar de uma relação indireta. Essa linha apresenta a legítima função de um signo: a representação dos elementos do mundo extralinguístico.

A ausência da base do triângulo permite afirmar que as palavras, enquanto símbolos convencionados pela sociedade, não são motivadas, mas mesmo, assim, o vínculo criado com o referente mantém-se, pois ele é necessário para o encadeamento das significações e, muito embora, o signo linguístico mantenha uma relação imputada com o referente, afastando a ideia do vínculo natural, entre nome e coisa nomeada, existem casos em que ocorrem motivações, sejam elas fonéticas, morfológicas ou semânticas. 
O próprio Saussure (1969) afirmou que há graus relativos de arbitrariedade, porém estes são explicados pelo linguista genebrino através das motivações internas ao sistema linguístico, uma vez que ocorre um tipo de empréstimo de palavras já existentes para a composição de novas palavras. A sua significação é possível pela oposição formulada a partir dos signos que lhes deram origem e dos outros signos que existem formulados pelos mesmos termos. Dessa forma, esse linguista considera plausível somente as motivações através das relações sintagmáticas e associativas existentes no sistema linguístico.

De acordo Guiraud (1980), todas as palavras são etimologicamente motivadas; acontece que essa motivação tende ao obscurecimento e depois ao apagamento.

Esse obscurecimento da motivação é tanto mais geral quanto mais ele é necessário, porque se tais associações se impusessem, elas poderiam acarretar uma restrição do sentido; [...] a palavra deve evocar o conjunto da coisa denominada e não apenas o caráter motivante, que, muitas vezes não é o essencial. [...] A motivação deve, portanto, apagar-se em proveito do sentido, porque, caso contrário ela se arriscaria a restringi-lo [...]. Mas a motivação é uma força criadora inerente à linguagem social, que é um organismo vivo de origem empírica; somente depois que a palavra é criada e motivada (naturalmente ou intralinguisticamente) é que as exigências da função semântica acarretam um obscurecimento dessa motivação etimológica, que pode, aliás, ao se apagar, trazer uma alteração do sentido. (GUIRAUD, 1980, p. 28)

Assim, para Guiraud (1980), a motivação das palavras pode ser interna ou externa ao sistema linguístico. Como motivação interna, têm-se as motivações morfológicas, no caso das derivações ou composições, em que se busca a motivação em palavras que já existem na língua. Já a motivação externa mantém um vínculo com o elemento extralinguístico. Essa motivação pode ser de caráter fonético, no caso das onomatopeias, ou metassêmico, quando ocorre uma mudança de sentido devido à similitude entre um significado de uma palavra já conhecida e o objeto que se deseja nomear, como nas metáforas pé-de-cabra, cabeça do prego, folha de papel, asa da xícara; ou por associação, como nas metonímias, em que o nome é formado a partir de uma relação de proximidade com o objeto que se deseja nomear, como por exemplo, pica-pau, girassol, beija-flor e joão-de-barro.

É importante lembrar nesse ponto a teoria semiótica de Peirce $(1975,2005)$, quando esse autor ressalta que as categorias do pensamento estão entrelaçadas e a primeiridade - em que se expõe a qualidade do objeto - e a secundidade - categoria em que se verifica uma relação 
de contiguidade entre o representamem e o objeto a que ela se refere - podem ser expressas na terceiridade, categoria dos símbolos.

Portanto, nos símbolos - nesta análise o signo linguístico - também é possível observar a presença de ícones, como as metáforas que expressam a ideia de "parece ser" ou "parece com" e a presença de índices, em que se corporifica a qualidade percebida no objeto a partir do nome, o que pode ser expresso pelas metonímias, quando se toma, por exemplo, uma parte pelo todo ou o produtor pelo produto.

Diante do exposto, verifica-se que o ato de nomear possui ao mesmo tempo um aspecto cognitivo, em que o homem utiliza o nome para descrever as características objetivas da coisa a ser nomeada, e um aspecto expressivo (GUIRAUD, 1980), em que o homem lança mão de um nome para mostrar suas impressões sobre aquilo que será nomeado; apresentando, assim, todo caráter criativo e dinâmico da língua, pois que a criatividade no ato de nomear também consiste em deslocar significados de palavras que nomeiam referentes já existentes para nomear outros referentes que não possuem um nome adequado à sua forma ou função.

Sendo assim, é cabível dizer que ao analisar os nomes que um povo atribui aos elementos do mundo extralinguístico, recuperam-se valores culturais capazes de resgatar a memória e a identidade de uma sociedade. Enquadram-se a esse princípio os nomes próprios de lugares, uma vez que, mais do que identificar uma localidade, a nomeação de um espaço geográfico possui uma carga de significação, não somente linguística, mas uma significação que perpassa por valores históricos e socioculturais correspondentes à época e ao espaço geográfico do denominador.

\section{Toponímia: conceitos}

A análise do objeto de pesquisa da Toponímia - o nome de aglomerados físicos e humanos - envolve estudos lexicológicos, no concernente à formação e o significado do signo toponímico, e ao mesmo tempo, perpassa pela Semiótica, pois se trata de um signo referencial, cujas características o aproximam dos signos denominados ícones e índices.

Além disso, por fazer parte do léxico comum, o topônimo também pode ser considerado como um "tesouro" a ser desvendado, uma vez que preserva o caráter cultural e identitário da formação de uma sociedade; sendo possível também, através de análises etimológicas, identificar, na forma toponímica, os estratos dialetais formadores do vernáculo de uma região. 
Dependendo da amplitude da pesquisa, à análise etimológica associam-se, sempre que possível, pesquisas de campo com verificação de documentos em arquivos públicos e entrevistas realizadas, no próprio local, com moradores na faixa etária acima de cinquenta anos e que tenham vivido na localidade por um longo período.

Essa última estratégia de pesquisa possui um caráter sociolinguístico, porém, na Toponímia, não se deseja mensurar valores, como se faz na pesquisa sociolinguística quantitativa $^{3}$. O intuito das entrevistas é adentrar no universo mnemônico cultural que os topônimos preservam, enquanto manifestações linguísticas de uma rede social, e associar as informações colhidas, in loco, com as verificações etimológicas e enciclopédicas, a fim de chegar à significação que o nome possui.

Dessa maneira, constata-se que o trabalho do toponimista é longo e necessita de muita atenção, uma vez que

no universo onomástico de uma determinada região, há nomes de lugares que são referencialmente identificáveis por pessoas que fazem parte de redes sociais afins. Isso ocorre porque tais nomes podem ser facilmente reconhecíveis pela cultura local, permanecendo registrados na memória dos membros daquela comunidade - são os chamados arquivos permanentes. Outras vezes, percebe-se, na mesma comunidade, uma impermeabilidade em muitos de seus topônimos - tratam-se dos arquivos opacos. (SEABRA, 2008, p. 1957.)

Os topônimos que integram os arquivos opacos sofrem a ação da dimensão temporal, o que faz com que a motivação inicial da denominação se torne desconhecida pelo falante. Se o topônimo se relaciona a aspectos da geografia de uma região, ele, provavelmente, será transparente, pois corresponde à descrição do lugar; entretanto quando se refere a processos psíquicos ou culturais, a tendência é o apagamento da motivação, a não ser que essa motivação esteja relacionada a processos históricos marcantes da área em estudo (SEABRA, 2008). Portanto, é necessário que as fontes de investigação do toponimista sejam confiáveis, para que não sejam levantadas interpretações equivocadas.

Como se verifica, o estudo toponímico baseia-se na característica principal do topônimo: a motivação semântica. É válido ressaltar que, mesmo sendo de forma indireta, os nomes possuem traços da cosmovisão que o homem possui, a qual corresponde ao tempo histórico e ao espaço cultural e geográfico a que pertence. Assim sendo, nomear é uma ação

\footnotetext{
${ }^{3}$ Para um maior esclarecimento sobre a metodologia da pesquisa sociolinguística, ver TARALLO, Fernando. A pesquisa sociolinguística. São Paulo: Ática, 1996.
} 
que pressupõe percepção do universo, conhecimento, comunicação e, consequentemente, a integração de todos os fatos socioculturais de uma sociedade.

Em se tratando dos fatos socioculturais, Guizzetti (1957 apud DICK, 1990a) classificouos em: biofatos, valores culturais ou religiosos que o homem atribui aos elementos da natureza; manufatos, produção de objetos utilizando matéria-prima da natureza física; sociofatos, organização da vida social de membros de uma mesma etnia e, por fim, mentefatos que correspondem à cultura espiritual de uma sociedade, o que envolve todo produto do psiquismo humano. Essas categorias agrupam fenômenos naturais, socioculturais e psíquicos que se intercruzam, fazendo parte de um mesmo universo linguístico.

Estando os topônimos integrados ao léxico comum de uma sociedade, é cabível a afirmação de que eles também representam as categorias culturais citadas por Guizzetti. Todavia, como esses são nomes que se encontram em função onomástica, cabe-lhes um diferencial em relação aos demais signos linguísticos: a motivação semântica.

Em outros termos, a utilização de um nome comum, no campo onomástico, indica que esse elemento da língua foi utilizado por existir algum vínculo com o elemento do mundo real, seja ele de cunho físico (aspectos geográficos) ou de cunho antropocultural (ligados a aspectos psíquicos, históricos e culturais que o homem apresenta, enquanto ser individual e social).

Redimensionando o triângulo semiótico de Ogden e Richards (1976), é possível estabelecer uma relação do que foi explicitado sobre a motivação semântica dos topônimos. Enquanto que na relação triádica, proposta por esses cientistas para representar a significação dos signos linguísticos, o vínculo entre o nome e o referente é indireto, na função toponímica há uma relação direta entre o nome e o lugar denominado, tornando-se a linha, antes pontilhada, em uma linha preenchida, como se vê no diagrama abaixo.

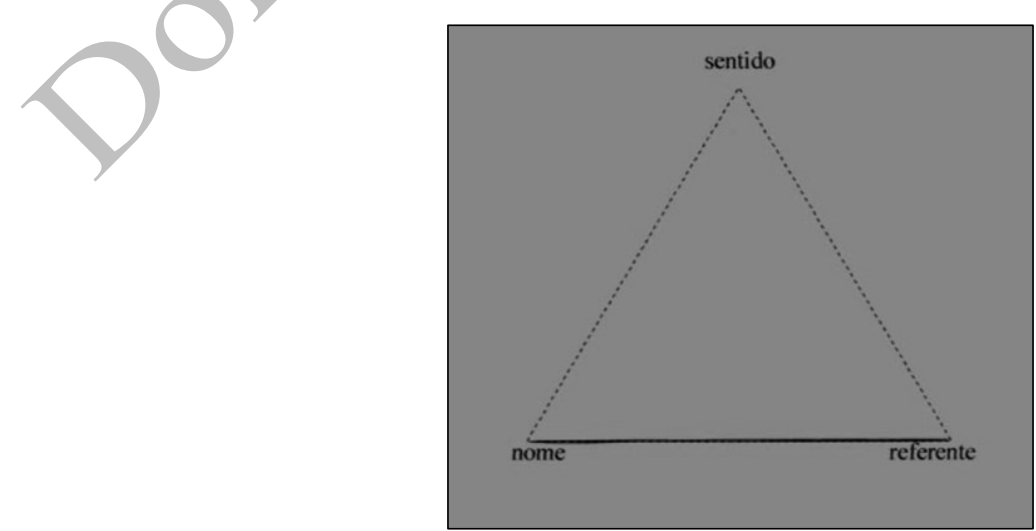

Figura 3 - A referência toponímica, baseada no triângulo semiótico de Ogden e Richards. Fonte: SEABRA, 2008, p. 1955. 
Essa relação direta entre o topônimo e o referente pode ser analisada à luz dos estudos semióticos proposto por Peirce $(1975,2005)$. Retomando alguns conceitos dessa teoria, é possível conceber o topônimo como uma forma linguística que apresenta aspectos inerentes aos três tipos de signo que Peirce propõe para ocupar o papel do representamem, no triângulo semiótico:

i. Ícone - signo que apresenta as qualidades puras, a primeira percepção que o intérprete possui sobre o elemento do mundo real. Esse signo desperta sugestões, impulsiona a mente a criar semelhanças possíveis, uma vez que trabalha no sentido do "parece ser";

ii. Índice - apresenta uma relação direta entre o representamem e o objeto, há uma relação de contiguidade entre o signo e aquilo que será apresentado. Além disso, este signo possui um caráter dêitico, passível de ser recuperado pelos interlocutores através da lembrança de detalhes que possam identificar o referente;

iii. Símbolo - este é um signo genuíno. O símbolo não identifica um ser individualizado, ele representa espécies dos elementos do mundo real. São conceitos de representação aprendidos a partir da interação linguística e estão sujeitos a acordos tácitos fundamentados em sociedade.

Peirce $(1975,2005)$ salienta que as três categorias do representamem estão interligadas. Sendo assim, os índices materializam as qualidades presentes nos ícones e ainda preservam suas particularidades. Também os símbolos, mesmo sendo signos convencionalizados, guardam características de ícones e índices.

Buscando compreender como os conceitos semióticos podem ser aplicados à Toponímia, basta pensar que todo topônimo é um nome próprio e, por conseguinte, possui a função de identificar, apresentando um caráter individualizado do objeto e mantém uma relação de contiguidade com aquilo que representa; além disso, possui também uma função dêitica. Apresenta, então, características de índices.

Todavia, os índices corporificam os ícones, os quais estão propensos a sugestões que indiquem semelhanças possíveis para relacionar o caráter qualitativo do referente à sua forma física; essa relação qualitativa é representada nos topônimos a partir do simbolismo linguístico: o nome.

Entende-se, pois, que os topônimos podem ser comparados a signos icônicos, principalmente quando se referem a aspectos geográficos, preservando, dessa forma, as categorias de índices e ícones. São signos motivados semanticamente, através de um processo 
metassêmico (GUIRAUD, 1980), constituído a partir de metáforas e metonímias: concepções ideológicas e sensitivas provocadas no denominador no ato da nomeação.

Nessa perspectiva, o nome é a parte que se refere ao todo: o lugar. Assim, o denominador utiliza-se de todos os traços - físicos ou culturais - que possam caracterizar um local e sirvam de indicação para o mesmo, incorporando-os ao nome. "Constroem-se, assim, pela palavra lexical, detalhes-referência para indicar um todo, semantizado metonimicamente." (DICK, 2001, p. 79).

O caráter simbólico do signo toponímico evidencia-se na discursividade, pois um topônimo legitima-se quando aceito pela sociedade, para depois atuar no âmbito das denominações onomásticas. Evidente que essa aceitação ocorre de maneira implícita a partir do processo comunicativo. Se aceitos pela sociedade, a tendência destes signos é de perpetuar-se, preservando, ao longo do tempo, formas linguísticas que podem indicar não só a sua origem, mas, também, a visão de mundo do grupo denominador. Por esse motivo, o topônimo também é visto pelos pesquisadores como um fóssil linguístico.

De fato, há topônimos que preservam formas linguísticas de origem dialetal desconhecida ao falante da língua. Tais elementos tornaram-se opacos devido ao distanciamento cronológico, porém, quando analisados etimologicamente, é possível ocorrer o reconhecimento da sua significação e do estrato dialetal de origem. Por exemplo, ao nomear um lugar, o índio da tribo Tupi verificava as características mais marcantes para descrever o ambiente e o nome correspondia fielmente a essa descrição. Nas palavras de Sampaio (1955, p. 19), os nomes de lugares para esses índios “[...] são, a bem dizer, verdadeiras definições do meio local".

Essa forma de nomear reitera a afirmação de Sapir (1969) sobre o ambiente: os aspectos ligados ao ambiente físico somente são passíveis de receber um nome se houver um interesse das forças sociais que agem sobre as ações do coletivo. A forma descritiva como os índios atribuíam nomes aos lugares devia-se à sua relação próxima com a natureza e à necessidade de localizar o lugar de maneira mais clara possível.

Tal fato pode ser exemplificado a partir de alguns elementos mórficos de origem indígena que estão presentes em diversos topônimos, por exemplo, o sufixo -tyba e suas

\footnotetext{
${ }^{4}$ Dick (1990a, p. 42) afirma que o primeiro a utilizar essa expressão foi o geógrafo francês Jean Brunhes, o qual considerava o topônimo um "fóssil da geografia humana".
} 
variantes, - tuba, - ndiba, - nduba (abundância, grande quantidade) ou o sufixo -mirim ( mi'ri: pequena cousa), ambos de origem tupi. Tais morfemas associados a outras formas do mesmo estrato dialetal conseguiram romper a barreira do tempo e preservam-se na geotoponímia brasileira.

Citam-se, por exemplo, os nomes de alguns topônimos da Ilha de Itaparica - BA, que ainda conservam esses elementos da língua tupi: Praia de Aratuba (ara: ave da família dos psitacídeos (periquito, arara) + -tuba : muitas aras); praia Jiribatuba (jiriba, giruba: variação de ji'riua (ave da família da momotídeos, com plumagem bastante colorida) +-tuba: muitas girubas); Ilha de Matarandiba (matara: redução da forma matarânna: árvore de madeira rija da família dos Renealmia sylvestris + -ndiba: mataranas em abundância); e Tassimirim - BA (tassai - formiga + -mirim: formiga pequena) ${ }^{5}$ praia localizada na Ilha de Boipeba - BA.

Essa maneira de nomear os lugares foi alterada durante o período da colonização, pois à toponímia brasileira de origem indígena foi agregada a visão de mundo do colonizador europeu, o qual trouxe para o Brasil um modelo onomástico comum na Europa do século XVI: a denominação referente aos preceitos católicos. Assim, a nomeação do território dominado correspondia à sua ideologia e, ao mesmo tempo, afirmava o seu poder de posse.

Em um primeiro momento, quando os jesuítas buscavam ganhar a confiança dos autóctones para catequizá-los, os topônimos de origem indígena foram unificados aos nomes de santos da religião católica: "[...] Santo Antônio do Surubuí, São Francisco de Gurupatuba, Nossa Senhora da Conceição de Mariuá, Santa Rita de Cássia de Itarandéua." (DICK, 1990a, p. 55). Percebendo que essa era uma forma de manter o idioma nativo, o Marquês de Pombal, em meados do século XVIII, ordena a eliminação total dos nomes indígenas, garantindo o domínio do idiomạ português. Entretanto,

a um imperativo da terra ou da gente, acabaram por desnaturar o quadro histórico da região. Ao se transpor motivos portugueses para uma realidade distinta, criou-se uma nomenclatura artificial, distante daquela primeira, que se adequava, por méritos naturais, aos acidentes que identificava. Logo, a restauração da toponímia indígena substituída seria medida perfeitamente compatível com o espírito de preservação do caráter nacional, que anima o topônimo e se ajusta à visão realística que ele deveria carregar. (DICK, 1990a, p. 56)

\footnotetext{
${ }^{5}$ Os significados desses étimos foram retirados dos dicionários de Cunha (1988), Barbosa (1955) e Bueno (1963). C. f. referências.
} 
Algumas localidades, com o passar do tempo, tiveram a sua origem indígena resgatada, mas o fato é que a visão do colonizador e do colonizado sobrevive na toponímia brasileira e a esse variado sistema onomástico integram-se topônimos de origem africana, revelando, assim, a identidade e a memória de povos vindos das diversas tribos da África. Portanto, para recuperar essa diversidade de identidades culturais que culminaram na formação do povo brasileiro, justifica-se o interesse de linguistas pelas motivações semânticas dos topônimos, uma vez que a denominação representa não só o lugar, mas também os valores socioculturais de uma sociedade.

\section{Aqui tem Cuscuz, Jenipapo e Cocão: motivações toponímicas das comunidades rurais}

\section{de Santo Antônio de Jesus}

Segundo Dick (1990b), o topônimo é o vínculo existente entre o objeto denominado e o denominador, pois é a partir desse produto gerado que será possivel recuperar as motivações semânticas que influenciaram o homem no ato da nomeação, já que suas percepções ficam registradas nos elementos linguísticos que constituem o topônimo.

É, pois, na realidade circundante, ou no chamado universo ambiental em que o homem se organiza, individual e comunitariamente, que se encontram as influências positivas ou negativas de sua própria experiência cultural, no mais amplo sentido. E é nessa mesma cadeia de possibilidades que os topônimos se estruturam e se distribuem em estratos de diversas naturezas. (DICK, 1990a, p. 61).

Partindo dessas premissas, Dick formulou um quadro taxonômico que apresenta classificações possíveis de enquadrar os topônimos brasileiros baseando-se em motivações físicas (aspectos geográficos) e antropoculturais (referentes ao meio social, cultural ou a aspectos psíquicos).

Através de estudos realizados, Dick verificou que os modelos de classificação europeia e norte-americana não eram adequados à realidade brasileira, a qual apresenta uma diversidade de nomeações geográficas. Percebendo a necessidade de uma terminologia científica que abrangesse a nomenclatura da geografia do Brasil, a autora publicou, em 1975, um primeiro modelo taxonômico com dezenove taxes (DICK, 1990a) e, em 1980, diante da necessidade de ampliar o sistema classificatório dos topônimos brasileiros, o quadro ganhou mais oito taxes, chegando ao total de vinte e sete. 
As taxes ${ }^{6}$ foram criadas a partir de um termo hiperônimo - termo genérico de origem greco-latina capaz de elucidar a categoria a qual o topônimo pertence - e o acréscimo do termo topônimo. Assim, por exemplo, observando o primeiro elemento do termo específico do topônimo Pedra Preta $(\mathrm{AH})$, tem-se uma classificação relacionada à motivação semântica de origem física. A taxe adequada para a classificação é, portanto, litotopônimo (lito- referente à origem mineral + o termo topônimo).

Os estudos com base no quadro taxonômico visam a uma análise sincrônica, dispensando um retorno histórico para que a significação da denominação seja alcançada. As verificações semânticas são feitas com base no material linguístico, o que em muito favorece as pesquisas toponímicas, pois dispensa a presença do denominador, o que nem sempre é possível, não só pelo distanciamento cronológico do ato da nomeação até o período da análise, como também pela dificuldade em realizar uma tarefa investigativa, in loco, quando se trata de uma área de pesquisa muito ampla, como no caso da formulação dos atlas toponímicos.

Isso não significa que associada às taxes não possa ser realizada uma pesquisa diacrônica que cuide também das mudanças denominativas sofridas pelos topônimos. Contudo, na perspectiva proposta por Dick (1990b), o estudo diacrônico limita-se à descrição isolada das taxes, no concernente a dados históricos que possam servir de apoio documental à pesquisa.

Utilizando o quadro taxonômico proposto por Dick (1990b), Almeida (2012) realizou um estudo das nomeações dos aglomerados humanos da área rural de Santo Antônio de Jesus, município localizado no Recôncavo Sul da Bahia. No corpus $^{7}$ em análise, foram encontradas as seguintes taxonomias de motivação física:

Fitotopônimos: Cocão, Espinheiro, Sapé, Cavaco, Camaçari, Gameleira, Gamelo, Jenipapo, Juerana, Sapucaia, Tabocal e Timbó.

\footnotetext{
${ }^{6}$ Para o maior esclarecimento sobre o quadro taxonômico proposto por Dick, veja DICK, Maria Vicentina de Paula Amaral. A motivação toponímica e a realidade brasileira. São Paulo: Arquivo do Estado de SP, 1990. e DICK, Maria Vicentina de Paula Amaral.. Toponímia e antroponímia no Brasil. Coletânea de estudos. 2. ed. São Paulo: [s.n], 1990.

${ }^{7} \mathrm{O}$ corpus desse trabalho foi obtido a partir das cartas topográficas, escala 1:000, disponíveis no site do IBGE. Cf. referências.
} 
$\checkmark$ Hidrotopônimos: Taitinga ${ }^{8}$, Água Comprida, Canta Galo9 , Riachão, Rio das Pedras, Riacho Dantas, Rio da Dona, Riacho das Teresa.

$\checkmark$ Geomorfotopônimo: Alto da Boa Vista, Alto do Morro, Baixa da Areia, Baixa do Morro, Ilha, Tabuleiro do Rio da Dona.

$\checkmark$ Litotopônimos: Barro Vermelho e Pedra Preta.

$\checkmark$ Zootopônimo: Serinhaém ${ }^{10}$.

Entre a taxonomia de motivação antropocultural, foram encontradas as seguintes classificações:

$\checkmark$ Sociotopônimos: Açougue Velho, Venda Nova, Mina do Sapé, Mina do Onha, Cuscuz, Engenho Velho, Jogo da Bola, Pela Porco.

$\checkmark$ Animotopônimo: Bom Jardim, Benfica, Boa Vista.

$\checkmark$ Hagiotopônimo: Bonfim, Bom Conselho, Nossa Senhora de Fátima.

$\checkmark$ Hierotopônimo: Cruzeiro do Riachão.

$\checkmark$ Antropotopônimo: Cunha, Casaca de Ferro.

$\checkmark$ Ergotopônimo: Cacimba, Chiqueiro, Escadinha, Roda D’Água.

$\checkmark$ Hodotopônimo: Ladeira do Sabão, Avenida.

$\checkmark$ Poliotopônimo: Comunidade São Bartolomeu, Vila Bonfim.

Ecotopônimo: Sobradinho.

Dirrematopônimo: Salto da Onça.

\footnotetext{
${ }^{8}$ Esse topônimo é de origem indígena, quando observada a etimologia tem-se o significado de "planta da água branca, referindo-se aos bambus que nascem ao longo das margens do rio; teria então a classificação de fitotopônimo. Entretanto, o nome dessas comunidades está ligado à importância que o rio desempenhou, durante séculos, nesse local, tanto que o nome Taitinga denomina duas comunidades rurais que foram formadas ao longo do seu curso. Esse foi um dos rios por onde navegaram os exploradores da região, além disso, engenhos, fazendas e sítios foram construídos próximo ao seu leito, visando a utilização da água para as atividades da lavoura. Antes que o rio ficasse poluído pelos dejetos dos esgotos que vinham da cidade, ele era rico em peixes e mariscos, servindo de fonte de subsistência e renda para as famílias ribeirinhas. Dessa forma, a classificação obtida relacionase a importância do rio, por isso é um hidrotopônimo.

${ }^{9}$ A origem histórica desse topônimo é incerta, entretanto, o nome da comunidade surge a partir da importância de um riacho chamado Canta Galo, utilizado pelos moradores da localidade. Muito provavelmente, o nome dado ao riacho se deve à fazenda existente no local, a qual era chamada de Fazenda Canta Galo. Por esse motivo, decidiuse atribuir a esse topônimo a taxonomia de hidrotopônimo, uma vez que o riacho era o ponto de referência do local.

10 Serinhaém- Topônimo de origem indígena. Correlato de "cirí-nhaě, a panela de siris; a bacia onde eles se refugiam; o viveiro dos siris. Pode proceder de cirí-nheē, os siris rumorejam
} 
Segundo Dick (1990a), a investigação toponímica apresenta um rico complexo linguístico-cultural, com inúmeros caminhos para os estudos científicos. Portanto, o topônimo não localiza apenas o espaço geográfico, ele também representa todo o espaço e com ele os fatos que ficaram marcados na memória, identificando e representando uma sociedade em seus hábitos, valores religiosos, econômicos e políticos, em suma, os topônimos são símbolos linguísticos que representam a cultura de um povo.

No que diz respeito aos topônimos das comunidades rurais de Santo Antônio de Jesus, foram encontrados elementos linguísticos das etnias formadoras do povo brasileiro: o índio, o português e o negro, com a maior predominância de topônimos de origem portuguesa. Em relação ao elemento indígena, foi possível perceber a sua marcante presença nesse território, tanto no aspecto descritivo que se reflete nos nomes dos lugares de origem indígena, os quais revelam a característica iconográfica concernente ao léxico toponímico, como também na íntima relação que o índio mantinha com a natureza, deixando como herança ao homem branco o artesanato, a culinária, a produção da mandioca e seus subprodutos, entre eles a farinha, o beiju, a goma e a puba.

Os topônimos indígenas encontrados nessa análise revelaram dois fósseis linguísticos, palavras que não se encontram em dicionários de língua portuguesa, compostos somente por morfemas de origem tupi - Taitinga e Serinhaém - e que são utilizados pela população, mas não são identificados como de origem indígena. Outro topônimo dessa mesma origem e que é considerado pela população como de origem portuguesa é o Cocão. A maioria das pessoas pensa que se trata de um coqueiro que dá muitos cocos grandes, entretanto, cocão é uma árvore que pode chegar a uma altura de até vinte e três metros e que se encontra em extinção nessa região, sendo mais comum na região Norte, em Pernambuco e ainda em países como Peru e Bolívia.

A raiz do topônimo Cocão é a palavra coca, que é agregada ao sufixo português aumentativo -ão. A palavra coca é derivada de kuka (CUNHA; MELO SOBRINHO, 1982), que vem da língua indígena quéchua ${ }^{11}$, originada nos Andes, a qual era falada pelos antigos incas e que, devido a sua funcionalidade, foi escolhida pelos espanhóis para ser a base da língua geral da América Hispânica (LAGORIO, 2009), assim como ocorreu com o tupi, língua falada pelos tupinambás, aqui no Brasil.

\footnotetext{
${ }^{11}$ A língua quéchua ainda é falada na Argentina, Bolívia, Equador e Peru.
} 
Outros topônimos como Sapé, Sapucaia, Juerana, Timbó, Jenipapo, Camaçari e Tabocal já se encontram nos dicionários da língua portuguesa; essa inclusão deve-se ao amplo contato entre os índios tupis e os portugueses, o que fez com que os luso-brasileiros adotassem muitos nomes tupis que retratavam a fauna e a flora brasileira (RODRIGUES, 2002).

Nos topônimos de origem portuguesa ou de origem híbrida, com motivação física, verificou-se o caráter descritivo, comum aos topônimos de origem indígena, como Taitinga e Serinhaém. Sendo assim, nomes como Água Comprida, Ilha, Pedra Preta ${ }^{12}$, Riachão, Alto do Morro, Baixa do Morro, Baixa da Areia, Rio das Pedras, Barro Vermelho e Tabuleiro do Rio da Dona revelam-se como símbolos iconográficos, pois representam as características descritivas geomorfológicas do espaço habitado.

As relações metonímicas expressas em muitos dos topônimos analisados apresentam a criatividade e a expressividade linguística do denominador. Assim, observam-se topônimos formulados tomando-se como base de nomeação um elemento pertencente ao lugar capaz de representá-lo, seja por relações físicas ou sociais; dessa forma, toma-se uma parte para representar o todo que é o próprio espaço geográfico. Encaixam-se nessa condição os topônimos Sapé, Timbó, Tabocal, Jenipapo, Camaçari, Sapucaia, Juerana, Cavaco, Cocão, Espinheiro, Gameleira, Cacimba, Cruzeiro do Riachão, Roda D’Água, Escadinha, Ladeira do Sabão e Sobradinho.

Maior expressividade ainda pode ser observada nos sociotopônimos, em que se tem como base de nomeação o local de trabalho, as atividades de trabalho, o produto comercializado ou atividades de lazer que eram realizadas. Assim, têm-se Açougue Velho, Mina do Sapé, Mina do Onha, Pela Porco, Engenho Velho, Jogo da Bola, Venda Nova.

Ainda há dois exemplos de relações metonímicas que revelam um maior grau de complexidade. O primeiro foi classificado como um dirrematopônimo por se tratar de uma expressão linguística baseada inicialmente em uma antonomásia, em que houve a substituição do nome do Sr. Antônio Neri de Souza pelo nome comum onça, tornando-se este uma alcunha para aquele, devido às semelhanças percebidas entre esses dois elementos.

Para entender melhor esse fenômeno, é preciso relembrar à época da mocidade do Sr. Antônio Neri de Souza, quando ele era comparado a uma onça, devido ao fato de ser namorador

\footnotetext{
12 Nessa comunidade houve uma intensa exploração do minério manganês, daí a motivação para a nomeação, a qual se deve a cor da pedra desse minério. Em outras comunidades do município de Santo Antônio de Jesus também houve a exploração desse minério: Mina do Sapé, Mina do Onha e Serinhaém.
} 
e ter um andar "manso" como de uma onça. Segundo seu neto, Sr. Evando, seu avô contava que os moradores diziam "Sai de baixo, gente, que lá vem a onça!” e, assim, esse senhor fícou conhecido como Antônio Onça. O Salto da Onça localiza-se às margens da rodovia BA-245 e do outro lado da pista está a comunidade do Açougue Velho, onde Sr. Antônio morava; tempos depois ele adquiriu uma área do outro lado da rodovia e as pessoas começaram a dizer que "Onça saltou de lado" , "Onça pulou de um lado pro outro" e daí então o local ficou conhecido como o Salto da Onça. Dessa forma, o topônimo deve ser analisado pela união dos dois termos do sintagma, pois se trata de um enunciado linguístico, sendo então classificado como

\section{dirrematopônimo.}

Vê-se, neste exemplo, como os processos cognitivos metáfora e metonímia entrelaçamse, a comparação metafórica termina como uma espécie de metonímia, a qual será utilizada em diversas enunciações que envolvem esse senhor, inclusive àquela que desencadeou o topônimo Salto da Onça.

O segundo exemplo diz respeito ao topônimo Casaca de Ferro, que também é uma antonomásia. A origem do nome deve-se a um senhor que morava no local, conhecido como João, o qual viveu nessa região por volta do final do século XIX ou início do século XX. Esse Sr. usava uma casaca com os botões de ferro e que não tirava de jeito algum; a casaca era semelhante àquelas que eram utilizadas pelos vigilantes das estações ferroviárias. Seu João ficou conhecido por Casaca de Ferro ou João Casaca. A casaca e o Sr. João mantinham uma representação de contiguidade, pois a casaca passou a representar o próprio Sr. João, assim, moradores que compravam os terrenos, no local, já compravam sabendo que o nome foi atribuído por ser o lugar onde morava ou havia morado o Sr. João Casaca de Ferro. Trata-se, portanto, de um antropotopônimo.

Duas relações metafóricas também merecem ser citadas, uma se refere ao topônimo Gamelo, o qual advém de uma comparação, segundo aquilo que conta a Sra. Alaíde Santos Souza, moradora do local, entre o caule da árvore gameleira e as gamelas produzidas pela madeira dessa árvore, assim surgiu o nome Gamelo, que, segundo Nascentes (1966), é uma variação linguística de gamela, vasilha usada para dar comida aos animais. A outra relação metafórica é com o topônimo Chiqueiro; o local foi assim chamado por se tratar de um lugar onde era possível encontrar uma aglomeração de porcos do mato, sendo interpretado e comparado aos chiqueiros construídos em sítios ou fazendas. 
O aspecto descritivo dos topônimos, as relações metonímicas e metafóricas que eles expressam, direcionadas ao contato do homem com o seu ambiente físico e social tornaram possível comprovar que a área rural de Santo Antônio de Jesus desempenhou e ainda desempenha papel de suma importância para essa cidade, pois o núcleo urbano consagrou-se em suas relações comerciais, com a grande contribuição do trabalho desenvolvido pelo homem rural em suas atividades agrícolas, extrativistas, pesqueiras ou artesanais, que garantiram e garantem o poder aquisitivo do homem simples do campo e faz girar a roda da economia santantoniense.

\section{Conclusão}

Diante do exposto e dos exemplos dos topônimos das comunidades de Santo Antônio de Jesus, percebe-se que a teoria semiótica relaciona-se diretamente às análises toponímicas, pois o nome do lugar estabelece um vínculo entre o denominador e o espaço circundante, envolvendo as relações culturais, sociais e econômicas.

Além dessas relações, que se concretizam em um espaço físico, é possível verificar, através do nome, os fenômenos descritos por Peirce $(1975,2005)$, no que diz respeito às qualidades percebidas pelo denominador, sobre o seu espaço físico, e que são expostas a partir de processos cognitivos como, por exemplo, as comparações metafóricas. Isso revela a criatividade e expressividade existentes no processo de denominação toponímica, uma vez que o denominador precisa utilizar as palavras que compõem seu repertório linguístico, criando associações e processos de formação de palavras, como derivação ou composição de palavras, para nomear o espaço geográfico.

Sendo assim, vê-se que, realmente, o signo é autogerativo, pois para explicar e identificar as observações que o homem possui a respeito do seu meio social, cria-se uma cadeia infinita de símbolos, os quais se legitimam a partir da interação social.

\section{Referências bibliográficas}

ALMEIDA, L. C. S. O léxico toponímico das comunidades rurais de Santo Antônio de Jesus. Salvador, 2012. 187f. Dissertação. (Mestrado em Língua e Cultura) Universidade Federal da Bahia- BA. Obra não publicada. 
BARbOSA, Pe. A. L. Pequeno vocabulário tupi-português. Rio de Janeiro: Livraria São José, 1955.

BUENO, F. da S. Grande dicionário etimológico-prosódico da língua portuguesa: vocábulos, expressões da língua geral e científica - sinônimos contribuições do tupi-guarani. São Paulo: Saraiva, 1963.

CUNHA, A. G. da; MELlO SOBRINHO, C. Dicionário etimológico Nova Fronteira da língua portuguesa. Rio de Janeiro: Nova Fronteira, 1982.

CUNHA, A. G. da. Dicionário histórico das palavras portuguesas de origem tupi. 4. ed. São Paulo: Companhia Melhoramentos; Brasília: Universidade de Brasília, 1998.

DICK, M. V. de P. A. A motivação toponímica e a realidade brasileira. São Paulo: Arquivo do Estado de SP, 1990a. $\overline{\text { [s.n], } 1990 \mathrm{~b} .}$

Toponímia e antroponímia no Brasil. Coletânea de estudos. 2. ed. São Paulo:

- Métodos e questões terminológicas na Onomástica. Estudo de caso: o Atlas Toponímico do Estado de São Paulo. Investigações linguísticas e teoria literária. Recife: UFPE, v. 9, p. 119-148, 1999.

. O sistema onomástico: bases lexicais e terminológicas, produção e frequência. In: OLIVEIRA, A. M. P. P. de; ISQUERDO, A. N. (Org.). As ciências do léxico: lexicologia, lexicografia, terminologia. 2. ed. Campo Grande: Ed. UFMS, 2001. p. 79-90.

GUIRAUD, P. A Semântica. Tradução de Maria Elisa Mascarenhas. 3. ed. São Paulo: DIFEL, 1980.

GUIZZETTI, G. F. La etnolinguística: del mundo del idioma al mundo de la cultura. Revista de Antropologia. São Paulo: Universidade de São Paulo, 1957 apud DICK, M. V. de P. A. A motivação toponímica e a realidade brasileira. São Paulo: Arquivo do Estado de SP, 1990a.

INSTITUTO BRASILEIRO DE GEOGRAFIA E ESTATÍSTICA. Download. Geociências. Mapas estatísticos. Censo 2010. Mapa municipal estatístico. Ba. Santo Antônio de Jesus. Diretório FTP <geoftp.ibge.gov.br>. Disponível em: $<$ ftp://geoftp.ibge.gov.br/mapas_estatisticos/censo_2010/mapa_municipal_estatistico/ba/santo antonio de jesus v2.pdf $>$. Acesso em: 15 out. 2009.

LAGORIO, C. A. Léxico, dicionários e tradução no período colonial hispânico. ALEA: estudos neolatinos, v. 11, n.2, jul./ dez., p. 309-320, 2009. Disponível em: < http://www.scielo.br/pdf/alea/v11n2/v11n2a09.pdf>. Acesso em: 14 jun. 2012.

NADIN, M. Processos semióticos e de informação: a semiótica da computação. Revista Digital de Tecnologias Cognitivas. Tradução Priscila Borges, 5. ed. ISSN: 1984.3585, São Paulo, 2011. Disponível em: $<$ http://www.nadin.ws/wp-content/uploads/2012/03/3-dossie-processossemioticos-e-de-informacao.pdf $>$. Acesso em: 19 mar. 2012. 


\section{NASCENTES, A. INSTITUTO NACIONAL DO LIVRO (BRASIL). Dicionário etimológico} resumido. Rio de Janeiro: INL, 1966.

OGDEN, C. K.; RICHARDS, I. A. O Significado de significado: um estudo da influência da linguagem sobre o pensamento e sobre a ciência do simbolismo. Tradução de Álvaro Cabral. 2. ed. Rio de Janeiro: Zahar Editores, 1976.

PEIRCE, C. S. Semiótica e filosofia: textos escolhidos de Charles Sanders Peirce. Tradução de Octanny Silveira da Mota e Leonidas Hegenberg. São Paulo: Cultrix, 1975.

. Semiótica. Tradução de José Teixeira Coelho Neto. São Paulo: Perspectiva, 2005.

RODRIGUES, A. D. Línguas brasileiras: para o conhecimento das línguas indígenas. São

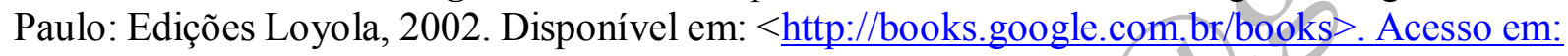
13 abr. 2012.

SAMPAIO, T. O Tupi na geografia nacional. 5. ed. São Paulo: Editora Nacional, 1955.

SAPIR, E. Língua e ambiente. In: SAPIR, E. Tradução de João Mattoso Câmara Junior. Linguística como ciência: ensaios. Rio de Janeiro: Acadêmica, 1969. p. 43-62.

SAUSSURE, F. de. Curso de Línguística Geral. Tradução de Antonio Chelini, José Paulo Paes e Izidoro Blikstein. São Paulo, Cultrix, 1969.

SEABRA, M. C. T. C. de. Referência e onomástica, 2008. Disponível em: $<$ http://www.filologia.org.br/ileel/artigos/artigo_442.pdf>. Acesso em: 14 set. 2009.

ULLMANN, S. Semântica: uma introdução à ciência do significado. 3. ed. Lisboa: Fundação Calouste Gulbenkian, 1964.

Artigo recebido em: 28.02.2013

Artigo aprovado em: 17.04.2013 